\title{
KERAGAMAN JENIS MUSUH ALAMI PADA SERANGGA HAMA PADI SAWAH DI KABUPATEN MINAHASA SELATAN
}

\section{DIVERSITY OF NATURAL ENEMIES SPECIES ON WET RICE-FIELD INSECT PESTS IN SOUTH MINAHASA REGENCY}

\author{
Mareyke Moningka, Dantje Tarore, dan Jeane Krisen*) \\ "Jurusan Hama dan Penyakit Tumbuhan, Fakultas Pertanian Unsrat Manado 95115
}

\begin{abstract}
The objective of this research was to know the diversity of natural enemies (parasitoid and predator) on wet rice-field, so that could be bread to control pest insects with a tactic that is easy, cheap, efficiently and environment safe. Catching a natural enemies species was conducted in district of Tumpaan and Tenga (which was the centre of rice production in South Minahasa Regency) by sweeping (using insects trap) and direct observation in the field. The specimen insect was brought to the laboratory for identified. Diversity was measured using Shannon-wavers, and then continued to decide the species abundance average level. The natural enemies species which were found consist of five ordos of predator (Araneida, Hemiptera, Odonata, Coleoptera, and Orthoptera); 10 families; and 16 species; two ordos, 10 families and 13 species of parasitoid. The result of variance analysis showed that the abundance average level $(\mathrm{J})$ of 29 species (predators and parasitoid) which were found almost the same and this value refer to value that almost the same on the diversity in species group $(\mathrm{H})$ during observation either the old crop stadia or the location of rice plant.
\end{abstract}

Keywords: Diversity, natural enemies, insect pest

\begin{abstract}
ABSTRAK
Penelitian bertujuan untuk mengetahui keragaman jenis musuh-musuh alami (parasitoid dan predator) pada serangga hama padi sawah agar dapat diketahui jenis musuh-musuh alami yang potensial dan dapat dikembangkan untuk mengendalikan serangga hama yang mudah, murah, efisien dan ramah lingkungan. Penelitian jenis-jenis musuh alami dilakukan secara penyapuan dengan net serangga dan observasi langsung di lapangan. Sampel serangga yang tertangkap dibawa ke laboratorium untuk diidentifikasi, dan dihitung. Untuk mengukur keanekaragaman jenis-jenis musuh alami (parasitoid dan predator) digunakan formula indeks keragaman Shannon-Wraver dan kemudian dilanjutkan dengan menentukan nilai tingkat kerataan kelimpahan spesies. Hasil penelitian menunjukkan bahwa jenis musuh-musuh alami yang ditemukan terdiri dari predator 5 ordo (10 famili) yaitu ordo Araneida, Hemiptera, Odonata, Coleoptera, dan Orthoptera; dengan jumlah 16 spesies. Parasitoid 2 ordo (10 famili) dengan jumlah 13 spesies. Hasil analisis keragaman memperlihatkan bahwa tingkat kerataan kelimpahan dari 29 spesies musuh alami (predator dan parasitoid) yang ditemukan adalah hampir sama nilai kerataannya kelimpahannya $(\mathrm{J})$ dan hal yang sama menunjukkan nilai yang tidak cukup berbeda pada keanekaragaman dalam kumpulan spesies $(\mathrm{H})$ selama pengamatan baik pada stadia umur tanaman padi yang berbeda maupun lokasi pertanaman padi.
\end{abstract}

Kata kunci: Keragaman, musuh alami, serangga hama

Eugenia Volume 18 No. 2 Agustus 2012 


\section{PENDAHULUAN}

Penelitian keragaman jenis musuh alami (parasitoid dan predator) pada serangga hama padi sawah di Kabupaten Minahasa Selatan perlu diteliti untuk menentukan strategi pengendalian hama yang tepat, agar populasi serangga hama tidak menimbulkan kerugian yang berarti pada tanaman padi sawah. Perkembangan teknologi pertanian untuk memacu peningkatan produksi pangan telah dilaksanakan melalui berbagai usaha antara lain penggunaan varietas unggul, pemupukan, irigasi, pengolahan lahan serta pengendalian hama dan penyakit. Adanya serangan hama dan penyakit pada tanaman merupakan faktor pembatas dalam peningkatan produksi frekuensi serangannya semakin lama semakin meningkat terutama di negara-negara yang sedang berkembang.

Di Provinsi Sulawesi Utara serangan hama pada tanaman padi datangnya silih berganti sebagai contoh hama wereng yang mulai menyerang tanaman padi sejak awal tahun 1970 kemudian mencapai puncaknya mulai pada awal tahun 1980 sampai pada akhir tahun 1988. Namun mulai awal tahun 1990 muncul kembali masalah hama penggerek batang padi, Trypoza sp. Serangga hama anggota ordo Hemiptera seperti Nezara viridula, Leptocorisa sp. dan Paraecosmetus sp., juga sering menyerang tanaman padi dengan mengisap bulir yang masih muda. Kepik Lygaeid, Paraecosmetus sp. adalah pengisap bulir yang baru pertama ditemukan di Kabupaten Bolaang Mongondouw tetapi kini telah menyebar di Kabupaten Minahasa dan daerah lain di Provinsi Sulawesi Utara (Sembel, 1989; Mangundap, 1990).

Salah satu cara penanggulangan hama yang umum dipergunakan oleh petani di Provinsi Sulawesi Utara, khususnya di Kabupaten Minahasa Selatan ialah melalui penyemprotan dengan insektisida, karena cara ini mudah untuk dilakukan dan dapat membunuh hama dengan cepat. Tanpa disadari oleh banyak orang terutama petani bahwa penggunaan pestisida yang berlebihan telah banyak membunuh musuh-musuh alami sehingga memungkinkan hama-hama serangga dapat berkembang tanpa kendali dan mengakibatkan terjadinya ledakan-ledakan populasi hama yang sangat merusak tanaman pertanian (Sembel, 1990).

Pada hakekatnya musuh-musuh alami dapat mengendalikan hama secara alami manakala lingkungan sekitar memungkinkan untuk berkembangnya musuh-musuh alami tersebut. Ekosistem pertanian di Indonesia yang beriklim tropis sebenarnya memiliki banyak jenis musuh alami (parasitoid dan predator) yang secara efektif dapat menekan populasi hama. Namun karena cara pengelolaan pertanian yang tidak tepat antara lain penggunaan pestisida yang berlebihan dan perombakan hutan untuk pembangunan serta bentuk-bentuk pembangunan lainnya yang tidak berwawasan lingkungan kadangkala lebih banyak membunuh musuh-musuh alami tersebut dari pada melindunginya. Penelitian tentang musuh-musuh alami serangga hama pada tanaman padi di Provinsi Sulawesi Utara, khususnya di Kabupaten Minahasa Selatan belum pernah dilakukan di kabupaten lain tetapi masih dalam cakupan yang sangat terbatas.

Penelitian ini bertujuan untuk mengetahui keragaman jenis musuh alami (parasitoid dan predator) pada serangga hama padi sawah agar dapat dikembangkan sebagai pengendalian hayati yang mudah, murah, efisien dan ramah lingkungan. Manfaat penelitian untuk menentukan strategi pengendalian secara terpadu dengan menitikberatkan pada pengendalian hayati di Provinsi Sulawesi Utara, khususnya di Kabupaten Minahasa Selatan serta menunjang program pembangunan di bidang pertanian yang lebih berwawasan lingkungan.

\section{METODE PENELITIAN}

Penelitian dilaksanakan di Kecamatan Tumpaan dan Kecamatan Tenga, kemudian dilanjutkan di Laboratorium Entomologi dan Hama Tumbuhan, Fakultas Pertanian Universitas Sam Ratulangi. Penelitian berlangsung sejak bulan September 2010 sampai dengan Agustus 2011.

\section{Predator}

Penelitian jenis musuh alami dilakukan secara penyapuan dengan net serangga dan 
observasi langsung di lapangan. Penyapuan dilakukan secara periodik yaitu dua minggu sekali. Serangga yang tertangkap dimasukkan ke dalam toples dan dibawa ke laboratorium untuk diidentifikasi, kemudian dihitung jumlah masingmasing predator yang tertangkap. Penyapuan dilakukan pada pagi hari.

\section{Parasitoid}

Pengambilan contoh parasitoid dilakukan dengan mengumpulkan telur, larva, nimfa atau pupa serangga hama untuk melihat apakah serangga tersebut telah diparasit oleh serangga parasitoid. Masing-masing telur, larva, nimfa dan pupa yang telah dikumpulkan dimasukkan ke dalam botol-botol, dimana setiap botol berisi satu spesimen dan dibawa ke Laboratorium Entomologi dan Hama Tumbuhan, Jurusan Hama dan Penyakit Tumbuhan Fakultas Pertanian Unsrat Manado. Parasitoid yang keluar dari serangga pradewasa diidentifikasi sampai ke tingkat genus dengan menggunakan kunci-kunci identifikasi yang tersedia.

Untuk mengukur keanekaragaman jenisjenis musuh alami (parasitoid dan predator) digunakan formula indeks keragaman Shannon Wraver sebagai berikut (Wilson dan Bossert, 1971 dalam Rimbing et. al., 1995).

Dimana :

$$
\mathrm{HS}=\sum_{i=1}^{S} P i \log e P i
$$

$\mathrm{HS}=$ Simbol keanekaragaman dalam sekumpulan spesies $\mathrm{S}$

$S=$ Jumlah spesies dalam kumpulan spesies

$\mathrm{Pi}=$ Kelimpahan relatif spesies ke-I dari 0-10 (misalnya bila spesies yang dihitung adalah yang kedua dari daftar ditulis $\mathrm{i}=2$; bila $10 \%$ dari semua individu tergolong spesies tersebut, $\mathrm{pi}=0,10$ )

\section{HASIL DAN PEMBAHASAN}

\section{Jenis-Jenis Musuh Alami}

Jenis musuh-musuh alami yang berhasil diidentifikasi dari seluruh koleksi yang ditemukan selama pengambilan sampel terdapat cukup banyak predator dan parasitoid yang dipandang berpotensi. Jenis musuh alami baik predator maupun parasitoid tersebut adalah terdiri dari tujuh ordo dan 10 famili yang tersebar pada 29 jenis/spesies. Khusus predator teridentifikasi lima ordo yaitu Araneida, Hemiptera, Odonata, Coleoptera, dan Orthoptera; serta tersebar pada 10 famili yang memiliki jumlah 16 jenis/spesies. Sedangkan parasitoid berjumlah dua ordo dengan 10 famili yang tersebar pada 13 jenis/spesies. Jenis-jenis musuh alami tersebut dapat dilihat pada Tabel 1.

Dari Tabel 1 menggambarkan bahwa musuh alami yang berperan sebagai predator pada hama-hama serangga tanaman padi di Kabupaten Minahasa sejak tanaman padi berumur 1, 2, dan 3 bulan didominasi oleh jenis laba-laba family Licosidae, Kumbang Coccinelidae, dan Odonata (Aquanidae). Selain itu pula terdapat kepik predator dari family Hemiptera, yaitu Reduviidae dan Miridae dan kumbang predator Staphylinidae. Walaupun ada beberapa jenis predator yang ditemukan dari penelitian ini yang cukup potensial yaitu jenis labalaba famili Agropidae, capung predator family Coemagridae dan belalang predator family Tettigonidae dan Gryllidae.

Dari hasil penelitian ditemukan 2 ordo yaitu Hymenoptera dan Diptera yang terdiri dari 13 spesies yaitu jenis parasitoid Compsilura sp (Tachinidae), Telenomus sp (Scelionidae), Brachymeria sp (Chalcididae), Trichogramma sp (Trichogrammatidae), Apanteles sp (Braconidae), Tetratichus sp (Eulopidae) dan Oencyrtus sp (Ichneumonidae).

\section{Parasitasi Parasitoid}

Keberhasilan pemeliharaan inang yang dikoleksi sangat menentukan jumlah spesies parasitoid. Hasil pemeliharaan yang sukses mendapatkan jenis parasitoidnya adalah pada sampel inang stadia telur dan larva sedang pupa tidak berhasil. Hasil identifikasi seperti pada Tabel 2; memperlihatkan bahwa walaupun hanya ditemukan dua ordo dan delapan jenis/spesies parasitoid tetapi jenis-jenis parasitoid tersebut diketahui sebagai musuh alami potensial yang menyerang atau menekan perkembangan beberapa serangga hama penting tanaman padi seperti Tryporyza sp.; 
Tabel 1. Jenis Musuh-Musuh Alami (Predator dan Parasitoid) yang Ditemukan di Desa Popontolen dan Radey Kabupaten Minahasa Selatan

(Table 1. Types of Natural Enemies (Predator and Parasitoid) were found in Popontolen and Radey Village South Minahasa Regency)

\begin{tabular}{|c|c|c|c|}
\hline No. & $\begin{array}{c}\text { Status } \\
\text { Musuh Alami }\end{array}$ & Ordo / Famili & Genus / Spesies \\
\hline 1 & Predator & Araneida / Licosidae & Lycosa sp. \\
\hline 2 & & Araneida / Licosidae & Callitrichia sp. \\
\hline 3 & & Araneida / Licosidae & Tetragnatha sp \\
\hline 4 & & Araneida / Agriopidae & Agriope sp. \\
\hline 5 & & Araneida / Licosidae & Oxyopes sp. \\
\hline 6 & & Hemiptera / Miridae & Cyrtorrhinus lividipennis \\
\hline 7 & & Hemiptera / Reduviidae & Polytoxus sp. \\
\hline 8 & & Odonata / Aquanidae & Aquanidae $\mathrm{A}$ \\
\hline 9 & & Odonata / Aquanidae & Aquanidae B \\
\hline 10 & & Odonata / Coemagridae & Agrionemis sp. \\
\hline 11 & & Coleoptera / Staphylinidae & Paederus sp. \\
\hline 12 & & Coleoptera / Coccinelidae & Chilomenes sexmaculatus \\
\hline 13 & & Coleoptera / Coccinelidae & Verrania sp. \\
\hline 14 & & Coleoptera / Coccinelidae & Chilocoris sp. \\
\hline 15 & & Orthoptera / Tettigonidae & Conocephalus sp. \\
\hline 16 & & Orthoptera / Gryllidae & Gryllidae \\
\hline 17 & Parasitoid & Diptera / Tachinidae & Compsilura sp. \\
\hline 18 & & Diptera / Syrphidae & Ischidion sp. \\
\hline 19 & & Diptera / Ephyridae & Nothipila sp. \\
\hline 20 & & Diptera / Pipunculidae & Tomosvariella sp. \\
\hline 21 & & Hymenoptera / Scelionidae & Telenomus sp. \\
\hline 22 & & Hymenoptera / Chalcididae & Brachymeria sp. \\
\hline 23 & & Hymenoptera / Braconidae & Apanteles sp. \\
\hline 24 & & Hymenoptera / Braconidae & Opius sp. \\
\hline 25 & & Hymenoptera / Trichogrammatidae & Trichogramma sp. \\
\hline 26 & & Hymenoptera / Eulopidae & Tetratichus sp. \\
\hline 27 & & Hymenoptera / Ichneumonidae & Ooencyrtus sp. \\
\hline 28 & & Hymenoptera / Ichneumonidae & Tryphon sp. \\
\hline 29 & & Hymenoptera / ichneumonidae & Amauromorpha sp. \\
\hline
\end{tabular}

Chilo sp.; dan Cnaphalocosis sp. Serangga hama dari genus Apanteles sp, Anagrus sp dan Gonatoceros sp. juga berpotensi sebagai parasitoid pada beberapa serangga hama padi sawah (DEPTAN, 2005).

Daya parasitasi juga dipengaruhi oleh kandungan nutrisi. De Sofa (2008) dalam Dien dan Dumalang (2010) menyatakan bahwa kandungan nutrisi merupakan faktor penting bagi perkembangan setiap makhluk hidup termasuk parasitoid. Kompleksitas kandungan nutrisi yang tersedia secara cukup dan baik akan menunjang perkembangan parasitoid. Faktor nutrisi sangat mempengaruhi aspek biologi, biokimia, fungsi metabolik dalam tubuh, dan toleransi terhadap faktor fisik lainnya dari parasitoid telur Leefmansia 
bicolor terhadap serangga hama Sexava nubila (Dien dan Dumalang, 2008). Berdasarkan

Eugenia Volume 18 No. 2 Agustus 2012 persentase telur Inanig terparası Ievirı uniggı dijumpai pada areal pertanaman kelapa yang ditumbuhi cover crops.

Habitat sekitar lahan persawahan dan umur tanaman padi mempengaruhi keanekaragaman Hymenoptera Parasitika yang ada didalamnya. Walaupun demikian, kondisi habitat sekitar lahan merupakan faktor utama yang menyebabkan perbedaan keanekaragaman parasitoid. Oleh karena itu, manajemen habitat sekitar lahan pertanian merupakan hal yang sangat penting untuk dilakukan sebagai upaya konservasi parasitoid pada lahan pertanian (Herlina dkk., 2010).

\section{Keanekaragaman Jenis Musuh Alami}

Pengukuran keanekaragaman jenis musuh-musuh alami predator dan parasitoid dengan formula indeks keragaman Shannon Wraver dan kemudian dilanjutkan untuk mengukur tingkat kerataan kelimpahan spesies. Hasil analisis keragaman memperlihatkan bahwa tingkat kerataan kelimpahan dari 29 spesies musuh alami (predator dan parasitoid) yang ditemukan adalah hampir sama nilai kerataan kelimpahannya $(\mathrm{J})$ dan hal yang sama menunjukkan nilai yang tidak cukup pulan spesies (T) selamla perigamionarn conion atau pengamatan baik pada stadia umur tanaman padi yang berbeda maupun lokasi pertanaman padi. Untuk lebih jelasnya dapat dilihat pada Tabel 3.

Kelompok musuh alami serangga hama tanaman padi sawah ada dari kelompok laba-laba, kelompok parasit serangga dan kelompok predator serangga (DEPTAN, 2005). Irshad (2001) dalam Rudiyanto (2010) menyatakan bahwa Menochilus sexmaculatus (F.) merupakan jenis kumbang kubah polifag terhadap beberapa serangga hama diantaranya Acyrthosiphon pisum (Harris), Aphis craccivora (Koch.), Aphis fabae (Theobald), Aphis gossypii (Glover), Aphis ruborum (Bor.), Myzus persicae (Sulz.), Rhopalosiphum maidis (Fitch), Dialeurodes citri (Ash), Diaphorina citri (Kuw.), Tetranychus orientalis (Mcg). Larva dan imago $\mathrm{M}$. sexmaculatus menunjukkan pemangsaan tipe II, dengan pengertian jumlah mangsa yang dimakan meningkat seiring dengan meningkatnya kepadatan populasi mangsa dan tidak meningkat meskipun kepadatan populasi mangsa meningkat setelah pemangsa kenyang (Rudiyanto dkk., 2010).

Tabel 2. Jenis Musuh-Musuh Alami Parasitoid yang Teridentifikasi Memarasit Inang Telur dan Larva Serangga Hama pada Tanaman Padi di Desa Popontolen dan Radey Kabupaten Minahasa Selatan

(Table 2. Types of Natural Enemies Identified as Parasitoid to the Eggs and Larvae of Insect Pests on Rice Plant in Radey and Popontolen Village South Minahasa Regency)

\begin{tabular}{|c|c|c|c|}
\hline $\begin{array}{c}\text { Sampel Stadia } \\
\text { Serangga yang } \\
\text { Terparasit }\end{array}$ & Jenis Parasitoid yang ditemukan & Ordo : Famili & Keterangan \\
\hline \multicolumn{4}{|c|}{ TELUR } \\
\hline 1. & Telenomus sp. & $\begin{array}{l}\text { Hymenoptera : } \\
\text { Scelionidae }\end{array}$ & \\
\hline 2. & Ooencyrtus sp. & $\begin{array}{l}\text { Hymenoptera : } \\
\text { Encyrtidae }\end{array}$ & \\
\hline 3. & Tetratichus sp. & $\begin{array}{l}\text { Hymenoptera : } \\
\text { Eutophidae }\end{array}$ & \\
\hline 4. & Trichrogramma sp. & $\begin{array}{l}\text { Hymenoptera: } \\
\text { Trichogrammatidae }\end{array}$ & \\
\hline \multicolumn{4}{|c|}{ LARVA } \\
\hline 1. & Compsilura sp. & $\begin{array}{l}\text { Diptera : } \\
\text { Tachinidae }\end{array}$ & \\
\hline 2. & Brachymeria sp. & $\begin{array}{l}\text { Hymenoptera : } \\
\text { Ohaicididae }\end{array}$ & \\
\hline 3. & Apanteles sp. & Hymenoptera : & \\
\hline 4. & Amauromorpha sp. & Hymenoptera : & \\
\hline
\end{tabular}


Moningka, M., dkk. : Keragaman Jenis Musuh Alami

PUPA

Tabel 3. Tampilan Tingkat Kerataan Kelimpahan Spesies Jenis Musuh-Musuh Alami (Predator dan Parasitoid) Sesuai Pengamatan dengan Metode Penyapuan pada Beberapa Stadia Umur Tanaman Padi di Desa Popontolen dan Radey Kabupaten Minahasa Selatan

(Table 3. Display of Average Level of Natural Enemies Species Abundance (Predator and Parasitoid) in Accordance to Observation with the Sweeping Method on Some Rice Plant Stadia/Age in Popontolen and Radey Village South Minahasa Regency)

\begin{tabular}{|c|c|c|c|c|c|c|}
\hline No. & $\begin{array}{l}\text { Umur Tanaman/ } \\
\text { Pengamatan }(\mathrm{I}, \mathrm{II})\end{array}$ & Lokasi & $\begin{array}{l}\text { Jumlah } \\
\text { Spesies } \\
\text { dalam } \\
\text { Kumpulan } \\
\text { Spesies } \\
\text { (S) }\end{array}$ & $\begin{array}{l}\text { Kelimpahan } \\
\text { Relatif spesies } \\
\text { (Pi) }\end{array}$ & $\begin{array}{l}\text { Keanekaragaman } \\
\text { Dalam kumpulan } \\
\text { Spesies } \\
\text { (H) }\end{array}$ & $\begin{array}{l}\text { Tingkat } \\
\text { Kerataan } \\
\text { Kelimpahan } \\
\text { Spesies } \\
\text { (J) }\end{array}$ \\
\hline 1 & 1 bulan / I & Popontolen & 74 & 1 & -2.721 & -0.632 \\
\hline 2 & 2 bulan / I & Popontolen & 100 & 1 & -3.070 & -0.667 \\
\hline 3 & 3 bulan / I & Popontolen & 129 & 1 & -3.002 & -0.618 \\
\hline 4 & 1 bulan / I & Radey & 81 & 1 & -2.866 & -0.662 \\
\hline 5 & 2 bulan / I & Radey & 95 & 1 & -3.205 & -0.704 \\
\hline 6 & 3 bulan / I & Radey & 96 & 1 & -2.995 & -0.652 \\
\hline 7 & 1 bulan / II & Popontolen & 75 & 1 & -2.729 & -0.632 \\
\hline 8 & 2 bulan / II & Popontolen & 129 & 1 & -3.081 & -0.634 \\
\hline 9 & 3 bulan / II & Popontolen & 124 & 1 & -2.936 & -0.609 \\
\hline 10 & 1 bulan / II & Radey & 73 & 1 & -2.832 & -0.660 \\
\hline 11 & 2 bulan / II & Radey & 97 & 1 & -2.908 & -0.635 \\
\hline 12 & 3 bulan / II & Radey & 81 & 1 & -2.985 & -0.679 \\
\hline
\end{tabular}

Kelompok musuh alami serangga hama tanaman padi sawah ada dari kelompok laba-laba, kelompok parasit serangga dan kelompok predator serangga (DEPTAN, 2005). Irshad (2001) dalam Rudiyanto (2010) menyatakan bahwa Menochilus sexmaculatus (F.) merupakan jenis kumbang kubah polifag terhadap beberapa serangga hama diantaranya Acyrthosiphon pisum (Harris), Aphis craccivora (Koch.), Aphis fabae (Theobald), Aphis gossypii (Glover), Aphis ruborum (Bor.), Myzus persicae (Sulz.), Rhopalosiphum maidis (Fitch), Dialeurodes citri (Ash), Diaphorina citri (Kuw.), Tetranychus orientalis (Mcg). Larva dan imago $M$. sexmaculatus menunjukkan pemangsaan tipe II, dengan pengertian jumlah mangsa yang dimakan meningkat seiring dengan meningkatnya kepadatan populasi mangsa dan tidak meningkat meskipun kepadatan populasi mangsa meningkat setelah pemangsa kenyang.

Anaxipha longipennis Serville adalah salah satu predator generalis yang dapat ditemukan pada ekosistem pertanaman padi pada habitat predator yang efektif untuk telur Lepidoptera dan nimfa wereng padi (Heong, 2002 dalam Karindah dkk., 2010). De Kraker (1996) dalam Karindah dkk. (2010), menjelaskan bahwa selama di pertanaman padi, A. longipennis dan $M$. vittaticolis aktif memangsa telur hama penggulung daun Cnaphalocrosis medinalis lebih dari $90 \%$. Eriborus argenteopilosus Cameron (Hymenoptera : Ichneumonidae) juga merupakan parasitoid larva pada Crocidolomia panovana Fabricius, Spodoptera litura Fabricius, dan Helicoverpa armigera Fabricius (Kalshoven, 1981 dalam Nelly, 2011).

\section{KESIMPULAN DAN SARAN}

\section{Kesimpulan}

Jenis-jenis musuh alami yang ditemukan terdiri dari 7 ordo, 20 famili dan 29 spesies; dengan rincian predator 5 ordo, 10 famili dan 16 spesies 
serta parasitoid dua ordo, 10 famili dan 13 spesies. Jenis-jenis parasitoid yang menyerang koleksi

Eugenia Volume 18 No. 2 Agustus 2012 al Iapang kemualan Dernası alıennara al laboratorium dan diidentifikasi adalah parasitoid yang potensial yaitu Telenomus sp; Ooencyrtus sp; Tetratichus sp; Trichogramma sp; Compsilura sp; Brachymeria sp; Apanteles sp; dan Amauromorpha sp.

\section{Saran}

Perlu melanjutkan penelitian potensi masing-masing parasitoid dan predator dalam menekan populasi serangga hama pada tanaman padi di Provinsi Sulawesi Utara khususnya di Kabupaten Minahasa Selatan, agar dapat diketahui parasitoid dan predator yang berpotensi dalam menentukan strategi pengendalian secara terpadu.

\section{DAFTAR PUSTAKA}

DEPTAN, 2005. Musuh Alami Serangga Hama Padi. Jurnal Penelitian. http://pustaka. litbang.deptan.go.id/agritek/s/tr1108.pdf.

Dien. M.F dan S. Dumalang. 2010. Potensi Parasitoid Leefmansia bicolor Untuk Mengendalikan Hama Kelapa Sexava nubilla di Kabupaten Kepulauan Talaud. Jurnal Eugenia. Vol.16:3 Hal. 181-189. Fakultas Pertanian : UNSRAT Manado.

Herlina, N., Sulasri dan Siti. 2010. Pengaruh Habitat Sekitar Lahan Persawahan dan Umur Tanaman Padi terhadap Keanekaragaman Hymenoptera Parasitika. Jurnal Entomologi Indonesia. Vol. 8:1 Hal. 17-26. PEl Bogor.

Mangundap, N. 1990. Penyebaran Paraeucosmetus sp. di Kabupaten Minahasa. Skripsi S1. Fakultas Pertanian Unsrat Manado.

Nelly, N., M. Rumansir dan E. Manoppo. 2011. Pengaruh Instar Larva Inang Spodoptera litura Fabricius (Lepidoptera : Noctuidae) terhadap Keberhasilan Hidup Parasitoid Eriborus argenteopilosus Cameron (Hymenoptera : Ichneumonidae). Jurnal
Entomologi Indonesia. Vol. 8:1 Hal. 36-44. PEl Bogor.

ysaan

Ivienocnilus sexmaculatus r. (woleoptera : Coccinelidae) terhadap Rhophalosiphum maidis Fitch (Homoptera : Aphididae). Jurnal Entomologi Indonesia Vol. 8:1 Hal. 1-7. PEI Bogor.

Rimbing, J dan G. S. J. Manengkey. 1995. Pemantauan Organisme Pengganggu Padi Sawah di Kabupaten Bolaang Mongondow. Fakultas Pertanian Unsrat Manado.

Sembel, D.T. 1989. Kepik Lygaeidae (Hemiptera) Pada Tanaman Padi di Kecamatan Dumoga. J. Res and Dev. Vol 1 (1); 59-62. Sam Ratulangi University, Manado. 1990. Beberapa Serangga Hama Pada Tanaman Padi dan Jagung. Proyek Pengembangan Perguruan Tinggi, Universitas Sam Ratulangi, Manado.

Karindah, S., D. Tarore dan M. Moningka. 2010. Ketertarikan Anaxipha longipennis Serville (Orthoptera: Gryllidae) terhadap Beberapa Jenis Gulma di Sawah sebagai Tempat Bertelur. Jurnal Entomologi Indonesia. Vol. 8:1 Hal. 27-35. PEl Bogor. 
